\title{
Factors affecting the mechanism of financial resource mobilization and utilization in building new countryside
}

\author{
Hoai Nam Nguyen ${ }^{a}$, Quoc Hoi Le ${ }^{b}$ and Xuan Hung Dinh ${ }^{c}$ and Dang Duc Nguyen ${ }^{d}$
}

${ }^{a}$ Vinh University, Vietnam

${ }^{b}$ National Economics University, Vietnam

${ }^{c} P h D$ candidate, Vinh University, Vietnam

${ }^{d}$ Nghe An Trading and Tourism College, Nghe An Province, Vietnam

CH R O N I C L E

A B S T R A C T

Article history:

Received: January 28, 2020

Received in revised format:

January 302020

Accepted: February 29, 2020

Available online:

March 2, 2020

Keywords:

Mechanism

Mobilization

Utilization

Financial resources

New countryside
This article attempts to examine the factors that affect the mechanism of mobilizing and utilizing financial resources in building new countryside in Vietnam. Based on the primary data gathered from 480 inhabitants, managers and enterprises in Nghe An province and through exploratory factor analysis (EFA) and linear regression, the findings show that viewpoint, orientations and objectives of socio-economic development are the most influential factors to the mechanism of the mobilization and utilization of financial resources for new countryside building, followed by structural organization and technical facilities, participating individual's perception, socio-economic environment and, lastly, specific characteristics of building new countryside.

\section{Introduction}

(C) 2020 by the authors; licensee Growing Science, Canada

The countryside in Vietnam has always played a vital role in the process of socio-economic building and development. Throughout history, the countryside has given birth to and retained various cultural identities, providing food for social consumption, materials for processing, agricultural goods for export, workforce for socio-economic activities, as well as consuming products from urban factories (Doan, 2017; Hoang, 2018). Acting on Resolution No. 26-NQ/TW dated August 5th, 2008 of the Party Central Committee on agriculture, farmers and rural areas, the Vietnamese Prime Minister enacted Decision No. 800/QĐ-TT dated June 4th, 2010, approving the National Target Program for building new countryside in the 2010-2020 period. Successful implementation of the program for building new countryside requires effective mobilization and utilization of resources, of which those of financial resources are the most important. Nghe An province, in the course of implementing the Nation Target Program for building new countryside, was faced with extremely challenging conditions: large surface area, various mountainous areas, complex terrains, low starting point, etc. However, with the participation of the whole political system and the support of the people, after 10 years of deploying the Program, the countryside building in Nghe An has been significantly improved. Of the 19 criteria that make up the program at the commune level, the average in Nghe An increased from 3,64 criteria/commune in 2010 to 15,96 criteria/commune in 2019, with 259 communes and 3 districts given the title of new countryside by the provincial People's Committee. That success is partly due to the mobilization and utilization of financial resources in building new countryside. As a matter of fact, in the period of 2010-2019, Nghe An mobilized more than 
$56.081,586$ billion dongs for building new countryside. However, mobilization and utilization of financial resources in building new countryside in Nghe An reveal some limitations, such as inefficient investments in building new countryside, primary dependence on state budget, large construction debts, sluggish pace of disbursement and implementation of several program contents, etc. One of the causes of those limitations is ineffective mobilization and utilization of financial resources in building new countryside in Nghe An, which has failed to encourage businesses, inhabitants, domestic and foreign organizations to participate. In order to improve the process of mobilization and utilization of financial resources for building new countryside, identifying contributing factors to the mobilization and utilization of financial resources for building new countryside in Nghe An is essential. This article will point out what the contributing factors are and which of them are the most influential to the mobilization and utilization of financial resources for building new countryside.

\section{Research model and hypothesis}

\subsection{Research model}

Based on existing literature (Scoones,1998; Ammons \& Lombardo, 2001; Simkova, 2008; Straka \& Tuzová, 2016; Doan, 2017; Hoang, 2018; Le, 2016; Ly; 2017), the authors build a model of contributing factors to mobilization and utilization of financial resources for building new countryside which comprise of the following factors: (1) characteristics of building new countryside; (2) socio-economic environment; (3) viewpoint, orientations and objectives of socio-economic development; (4) perception of participants; (5) structural organization and technical facilities. The aforementioned factors have direct effect on the mechanism of mobilization and utilization of financial resources for building new countryside. The completion of mobilization and utilization of financial resources for building new countryside must be in consideration of these factors in order to achieve high efficiency and probability.

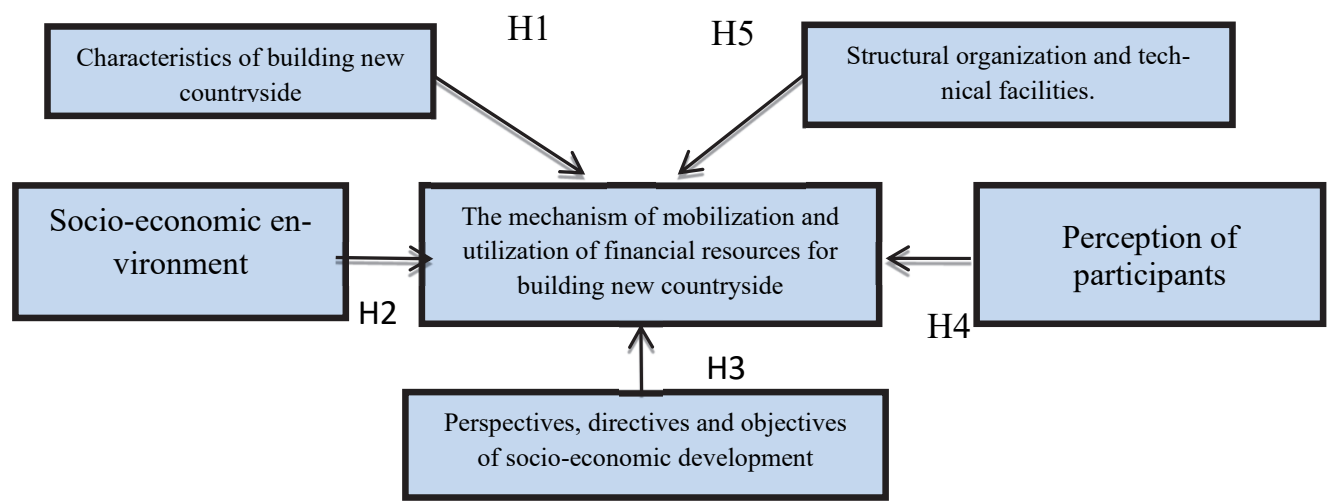

Fig. 1. Research model

\subsection{Research hypothesis}

2.2.1. Characteristics of building new countryside affecting mobilization and utilization of financial resources for building new countryside

According to Le (2016), Doan (2017) and Ly (2017), building new countryside has a variety of characteristics, including funding requirements, time consuming, slow payback, large construction scale with weather condition dependence and complex construction structures, adequate requirements of constructions in terms of technique, durability, construction and finance, as well as the level of inhabitants' social-cultural knowledge and perception. With these characteristics, financial resource mobilization requires an appropriate mechanism. The direct subject of the outcome of financial resource utilization in building new countryside is local communities. Accordingly, this characteristic involves more comprehensive exposition and transparency in mobilization and utilization of financial resources and more efficient mobilization of financial resources of the communities in building new countryside (Ly, 2017). The possibility of loss and waste of financial resources in building new countryside is high due to the long period of investment in building new countryside, complex and heterogeneous terrain and high spending content, with many subjective and objective risks. Consequently, the loss and waste of financial resources in the implementation process are quite significant (Le, 2016; Ly, 2017). These characteristics spark the need for organizing and managing the mobilization and utilization of financial resources for building new countryside strictly, scientifically in order to minimize the loss and waste and to prevent and manage risks that may arise during the implementation of new rural construction. Therefore, the development of mechanisms for mobilizing and utilizing financial resources for building new countryside should take into account these characteristics. Thus, the authors propose the hypothesis

$\mathrm{H}_{1}$ - Characteristics of building new countryside affect the mechanism of mobilizing and utilizing financial resources for new rural construction.

\subsubsection{Socio-economic environment affecting mobilization and utilization of financial resources for building new countryside}

Mobilization and utilization of financial resources are carried out in the socio-economic environment (Doan, 2017; Hoang, 2018). The socio-economic environmental factors are expressed with specific indicators such as growth, economic structure, 
income per capita and people's spiritual life (Le, 2016; Ly, 2017). From the economic perspective, the building of new countryside is generally the utilization, consumption of resources and social wealth. These indicators will positively reflect a high level of local socio-economic development, high living standards, which means that the local financial resources will be more abundant, making the building of new countryside favorable (Ly, 2017). Therefore, for each different socio-economic environment, the mechanism of mobilizing and utilizing financial resources will make appropriate adjustments to ensure effective management of mobilization and utilization of financial resources. At present, the socio-economic trend is going to develop faster and become more integrated. People will have a higher demand for material and spiritual life. Integration brings new knowledge and new development trends. All of these will be the challenges to the renovation of the mobilization and utilization of financial resources. A mechanism to mobilize and utilize financial resources for building new countryside is a financial management system suitable to the national and local socio-economic development levels, helping to mobilize multiple financial resources for rural areas as well as promoting efficiency in financial management (Nguyen, 2019). Therefore, the authors propose the hypothesis

$\mathrm{H}_{2}$ - The local socio-economic environment affects the mechanism of mobilizing and utilizing financial resources for new countryside construction.

\subsubsection{Orientations and objectives of socio-economic development affecting the mechanism of financial resource mobilization} and utilization in building new countryside

The mechanism for mobilizing and utilizing financial resources to build new countryside has to follow the orientations and objectives of economic development of the state and localities (Scoones, 1998; Straka \& Tuzová, 2016; Diu, 2017; Doan, 2017). The development of mechanisms for mobilizing and utilizing financial resources for building new countryside must conform to the development orientation of the country and locality in each period. This is the direct basis for building a mechanism to mobilize and utilize financial resources for building new countryside. In localities with favorable development conditions, the amount of capital needed to fulfill the program criteria will be reduced because the evaluation criteria are almost reached (Doan, 2017). For poor localities with poor rural infrastructure, the local government is in a greater need for socio-economic development, which requires greater contribution from the rural population (Doan, 2017). The mobilization and utilization of financial resources always serve the socio-economic development goals for each locality in general and for new rural construction in particular (Hoang, 2018). For this reason, there should be a more open mobilization mechanism. Longterm, stable development strategies are favorable conditions for investors to feel secure to invest capital, which is a decisive condition for attracting investment of financial resources (Doan, 2017; Hoang, 2018). In addition, local governments need to create a favorable and equal business environment, have policies to encourage investment, etc. to improve the mobilization of financial resources for building new countryside and contributing to socio-economic development (Doan, 2017). Therefore, the authors propose hypothesis.

$\mathrm{H}_{3}$ - Viewpoint, orientations and objectives of local socio-economic development affect the mechanism of mobilizing and utilizing financial resources to build new countryside.

\subsubsection{Participants' perception affecting mobilization and utilization of financial resources for building new countryside}

Since people are the subject of management activities, which are strongly influenced by human perception. The awareness of the participants when developing the mechanism of mobilizing and utilizing financial resources to build new countryside refers to the governments, management officials and citizens who carry out the program (Diu, 2015; Ly, 2017; Hoang, 2018). In essence, the difficulties and constraints in the mechanism of mobilizing and utilizing financial resources for new countryside cannot be identified more clearly than by the managers and the people themselves. The manager is the person who grasps the understanding of the mechanism, working process, thereby digging out the shortcomings in the operation through which they can propose to improve the mechanism. Therefore, the perception and attitude of the manager plays a very important role (Hoang, 2018). Although a mechanism may be effective, when it comes into operation, if the manager does not have the knowledge, experience and practical skills, the implementation of the mechanism will be difficult and entangled. There have been cases where the limited knowledge of management skills led to misunderstanding of the mechanism and misapplication. Awareness of rural people is lower than that of urban residents due to limited access to information and the education system (Diu, 2015; Ly, 2017). If people believe in the leadership of local officials, they will be aware of their specific roles, thereby actively and voluntarily contributing resources to building new countryside. Given this basis, the authors propose this hypothesis

$\mathrm{H}_{4}$ - Participants' perception that affects the mechanism of mobilizing and utilizing financial resources builds new countryside.

\subsubsection{Structural organization and technical facilities, and mobilization and utilization of financial resources for building new} countryside

In the course of developing, operating and perfecting the mechanism of mobilizing and using financial resources, structural organization and technical facilities are considered to be the important factors (Ammons and Lombardo 2001; Straka \& Tuzová, 2016; Le, 2016; Ly, 2017). Structural organization represents decentralization in the management of domains of an agency or organization. Currently, the apparatus for building new countryside is organized from the central to local levels. Structural organization of the local government in general and of the local Steering Committee for building new countryside in particular needs to conform to the following: functional departments and divisions must coordinate in a uniform manner in 
carrying out tasks; the apparatus of the new countryside construction steering committee must have all relevant components and a unified and coordinated operation to ensure regular attention to and supervision of program (Ly, 2017). The organization of new countryside building is sufficiently guaranteed by the budget according to standards, so less attention is sometimes paid to the workload and nature of the program. This is one of the reasons for the decline in working efficiency and the hindrance in the process of reforming and operating new management mechanisms. In addition, technical facilities are also the premise for modernizing the management, aiding the management mechanism in achieving the set goals. Therefore, the authors propose the hypothesis

$\mathrm{H}_{5}$ - Structural organization and technical facilities affect the mechanism of mobilization and utilization of financial resources for building new countryside.

\section{Research methods and measurement scale}

\subsection{Research methods}

This research is conducted through two main steps: preliminary research through qualitative method and formal research through quantitative method. The preliminary study was conducted by qualitative research method with group discussion technique and expert interview. The purpose of this study is to adjust and supplement the scale of factors affecting the mobilization and utilization of financial resources to build new countryside. Formal research is carried out by quantitative approach. Information collected is processed by using SPSS software. The study is based on the primary data collected from the questionnaire-based interviews with people, managers, businesses in Nghe An province through the method of direct distribution of questionnaires. Samples were selected by using a convenient sampling method. The sample size depends on the expectation of reliability, the method of data analysis, the parameters to be estimated, and the distribution rules of the selected sets. According to Hair et al. (2010), if the study uses EFA (Exploratory Factor Analysis), the sample size must be at least 100 (or larger). In general, the sample size must be at least 5 times larger than the measurement variable, which means there must be at least 5 observations for every measurement variable. In similar fashion, Hoang and Chu (2008) contend that in the EFA, normally the number of observations must be at least 4 or 5 times the number of observed variables in factor analysis. The model of evaluating the contributing factors has 31 measurement variables. Complying with the rule of 5: 1 , the minimum sample size is $31 \times 5=155$. In order to get a large enough sample size, the authors decide to choose 480 as the sample size. The survey results collect 480 satisfactory votes in the result analysis. The authors enter data and at the same time removed unsatisfactory questionnaires. The authors encode and enter the data, then the data is processed by SPSS 20. The data of the study is analyzed through the following steps: Verifying the reliability of the scale by analyzing Cronbach's alpha; Exploring factor analysis (EFA); Analyzing linear regression.

\subsection{Measurement scale}

Based on the results of qualitative approach and the research results of previous studies, the authors give a specific scale for the variables in the model as follows:

Table 1

The scales in the research model

\begin{tabular}{|c|c|c|}
\hline Code & Measurement scale & Sources \\
\hline I & Characteristic scale of building new countryside & \multirow{6}{*}{$\begin{array}{l}\text { Le (2016), Ly (2017), } \\
\text { Doan (2017), Nguyen (2019) }\end{array}$} \\
\hline D1 & Building new countryside requires resources & \\
\hline D2 & The scale of building new countryside is large & \\
\hline D3 & The time it takes to build new countryside is often long & \\
\hline D4 & The source of capital for new countryside is diverse & \\
\hline D5 & The people are the main beneficiaries of the new countryside program & \\
\hline II & Scale of socio-economic environment & \multirow{6}{*}{$\begin{array}{l}\text { Straka \& Tuzová, 2016, Le } \\
\text { (2016), Ly (2017), Doan (2017) } \\
\text { Hoang (2018) }\end{array}$} \\
\hline M1 & Nghe An economic growth increases year by year & \\
\hline M2 & Economic restructuring in Nghe An is reasonable & \\
\hline M3 & Per capita income in Nghe An is improved & \\
\hline M4 & The spiritual life of rural people in Nghe An is improved & \\
\hline M5 & Business environment in Nghe An is favorable & \\
\hline III & Scale of orientations and objectives of socio-economic development & \multirow{7}{*}{$\begin{array}{l}\text { Scoones (1998), } \\
\text { Straka \& Tuzová, 2016, Diu } \\
(2017) \text {, Doan (2018), Hoang } \\
(2018)\end{array}$} \\
\hline Q1 & Building a new countryside to motivate Nghe An socio-economic development & \\
\hline Q2 & Building Nghe An to become the economic center of the Northern Central Region & \\
\hline Q3 & Socio-economic development associated with environmental protection & \\
\hline Q4 & Economic restructuring towards industrialization and - modernization & \\
\hline Q5 & Long-term and stable socio-economic development strategy in Nghe An & \\
\hline Q6 & Agricultural development in Nghe An towards high technology & \\
\hline IV & Scale of participants' perception & \multirow{5}{*}{$\begin{array}{l}\text { Diu (2015), Hoang (2018), Le } \\
(2016), \\
\text { Ly (2017) }\end{array}$} \\
\hline N1 & Officials are aware of the important role of building new countryside & \\
\hline N2 & Officials at all levels know the contents of the new countryside program & \\
\hline N3 & Officials at all levels and local mass organizations exemplify in building new countryside & \\
\hline N4 & People believe in the leadership of local officials & \\
\hline
\end{tabular}


Table 1

The scales in the research model (Continued)

\begin{tabular}{|c|c|c|}
\hline Code & Measurement scale & Sources \\
\hline $\mathbf{V}$ & Scale of structural organization and technical facilities & \multirow{7}{*}{$\begin{array}{l}\text { Ammons and Lombardo (2001) } \\
\text { Simkova (2008), Straka \& Tu- } \\
\text { zová, 2016, Le (2016), Ly (2017) }\end{array}$} \\
\hline B1 & $\begin{array}{l}\text { The commune and village steering committees carry out the program of building new countryside } \\
\text { effectively }\end{array}$ & \\
\hline B2 & Management responsibilities for financial resources are clearly specified & \\
\hline B3 & Model of managing financial resources in Nghe An is reasonable & \\
\hline B4 & Organizational structure is built in a streamlined and efficient manner & \\
\hline B5 & $\begin{array}{l}\text { Technical facilities regulate the mechanism of mobilization and utilization of financial resources to } \\
\text { meet the demands }\end{array}$ & \\
\hline B6 & People are involved in the process of building new countryside & \\
\hline VI & Scale of mechanism for mobilizing and utilizing financial resources to build new countryside & \multirow[t]{6}{*}{ Doan (2017), Hoang (2018) } \\
\hline H1 & $\begin{array}{l}\text { The mechanism of mobilizing and utilizing financial resources to build new countryside in Nghe } \\
\text { An ensures validity }\end{array}$ & \\
\hline $\mathrm{H} 2$ & $\begin{array}{l}\text { The mechanism of mobilizing and utilizing financial resources to build new countryside in Nghe } \\
\text { An ensures efficiency }\end{array}$ & \\
\hline H3 & $\begin{array}{l}\text { The mechanism of mobilizing and utilizing financial resources to build new countryside in Nghe } \\
\text { An ensures economization }\end{array}$ & \\
\hline $\mathrm{H} 4$ & $\begin{array}{l}\text { The mechanism of mobilizing and utilizing financial resources to build new countryside in Nghe } \\
\text { An ensures conformity }\end{array}$ & \\
\hline H5 & $\begin{array}{l}\text { The mechanism of mobilizing and utilizing financial resources to build new countryside in Nghe } \\
\text { An ensures stability }\end{array}$ & \\
\hline
\end{tabular}

\section{Research results}

\subsection{Preliminary results of measurement scale}

The scales are preliminarily assessed through two main tools: (1) Cronbach alpha reliability coefficient and (2) EFA (Exploratory Factor Analysis) method.

Testing Cronbach alpha reliability of the scale: The reliability of the scale involves testing the consistency of the scale to confirm that the scale can measure the necessary concept. If the Alpha value is low, then there is at least one unreliable variable and that variable must be identified through the process of analysis. Depending on whether the research context is completely or relatively new to the research context, the authors determine that the Alpha coefficient must be greater than 0.6; 0.7 or 0.8 . The Cronbach's Alpha coefficient of 0.6 or higher may also be considered for use in the new research context. The usable scale must have a correlation coefficient of the total variable (Corrected Item - Total Correlation) of 0.3 or more (Hair et al., 2010). Contribution value is reflected by the correlation coefficient of the total variable (Corrected Item - Total Correlation). Observed variables with correlation coefficient of the total variable less than 0.3 will be excluded. The results are shown in Table 2.

Table 2

The results of testing the reliability of the scale

\begin{tabular}{lc}
\multicolumn{1}{c}{ Factor } & $\begin{array}{c}\text { The minimum correlation coeffi- } \\
\text { cient of total variable }\end{array}$ \\
\hline Characteristics of building new countryside & 0.474 \\
Local socio-economic environment & 0.662 \\
Local viewpoint. orientations and objectives of socio-economic development & 0.677 \\
Perception of participants & 0.711 \\
Structural organization and technical facilities. & 0.847 \\
The mechanism of mobilizing and utilizing financial resources to build new countryside & 0.899 \\
\hline
\end{tabular}

The test results of Cronbach's Alpha Coefficient are all greater than 0.6. The correlation coefficients of the variable are all over 0.3. Therefore, all of these variables are used in the subsequent EFA. EFA is used to categorize the initial observation variables into meaningful new factors, as well as discover the underlying structure between the research concepts (initial factors) according to actual data to form new factors that are meaningful to the actual research. The authors conducted an EFA for all observed variables with Varimax rotation (perpendicular rotation of factors to minimize the number of large coefficients at the same factor, making it easy to explain the observed variables closely related to a factor), eigenvalue $>1.0$ to find out the factors representing the variables because, according to Hair et al. (2010), Varimax allows full rotation of factors to minimize the number of variables with large coefficients at the same factor. The ability to explain the factors will, therefore, increase. According to Hair et al. (2010), criteria for the EFA are as follow:

- KMO index with a value in the range of 0.5 to 1 is suitable for EFA;

- Factor loading: single correlation coefficient between variables and factors $>0.5$;

- Total Variance Explained: total variance explained. Usually the total variance extracted (Total Variance Explained) $>50 \%$;

- Eigenvalue of the variability explained by each factor $>1$; 
The results of factor analysis for the independent variables show that 5 factors were extracted including: Characteristics of building new countryside; Socio-economic environment; orientations and objectives of socio-economic development; Perception of participants; Structural organization and technical facilities. The results of simultaneous EFA for 26 observed variables of 5 independent variables show that 5 factors were extracted at Eigenvalue $>1, \mathrm{KMO}$ index $=0.884$ (satisfactory must be $>0.5$ ). The Bartlett test results were $\mathrm{p}=0.000<5 \%$, which means that the variables are correlated with each other and are eligible for factor analysis through the EFA test. The total explained variance when the factor group is drawn is $69,977 \%$ (greater than 50\%). The results of the rotation factor matrix analysis show that the observed variables are basically downloaded to the original factor with the lowest load factor of 0.526 and the highest of 0.907 to ensure the requirements in factor analysis (particularly in Table 3).

Table 3

Results of EFA - exploratory factor analysis

\begin{tabular}{|c|c|c|c|c|c|c|}
\hline & \multicolumn{6}{|c|}{ Rotated Component Matrix } \\
\hline & \multirow{2}{*}{ Factor } & \multicolumn{5}{|c|}{ Component } \\
\hline & & 1 & 2 & 3 & 4 & 5 \\
\hline 1 & Q4 & 0.807 & & & & \\
\hline 2 & Q2 & 0.793 & & & & \\
\hline 3 & Q1 & 0.774 & & & & \\
\hline 4 & Q3 & 0.763 & & & & \\
\hline 5 & Q5 & 0.760 & & & & \\
\hline 6 & Q6 & 0.729 & & & & \\
\hline 7 & B3 & & 0.822 & & & \\
\hline 8 & B4 & & 0.785 & & & \\
\hline 9 & B2 & & 0.766 & & & \\
\hline 10 & B5 & & 0.711 & & & \\
\hline 11 & B6 & & 0.669 & & & \\
\hline 12 & B1 & & 0.635 & & & \\
\hline 13 & M3 & & & 0.907 & & \\
\hline 14 & M5 & & & 0.907 & & \\
\hline 15 & M4 & & & 0.668 & & \\
\hline 16 & M2 & & & 0.662 & & \\
\hline 17 & M1 & & & 0.651 & & \\
\hline 18 & D4 & & & & 0.840 & \\
\hline 19 & D1 & & & & 0.833 & \\
\hline 20 & D2 & & & & 0.819 & \\
\hline 21 & D5 & & & & 0.800 & \\
\hline 22 & D3 & & & & 0.526 & \\
\hline 23 & N3 & & & & & 0.751 \\
\hline 24 & N4 & & & & & 0.728 \\
\hline 25 & N2 & & & & & 0.726 \\
\hline 26 & N1 & & & & & 0.723 \\
\hline
\end{tabular}

The results of factor analysis for the dependent variable of mobilization and utilization of financial resources for building new countryside show that KMO coefficient $=0.858$ satisfies condition $\mathrm{KMO}>0.5$, proving that factor analysis is suitable with available data. The Bartlett test results with $p=0.000<5 \%$, which means that the variables are correlated with each other and are eligible for factor analysis through the EFA test. Principal Component Analysis results show that a group of factors can be drawn from 5 observed variables of the dependent variables. The total variance explained when the factor group is drawn is $79,148 \%$ (greater than $50 \%$ ). The results of the rotation factor matrix analysis show that all observed variables of the dependent variables have satisfactory load factors $(>0.5)$, meaning that the observed variables are of practical significance and correlated tightly with elements corresponding to the dependent variable on mechanism of mobilization and utilization of financial resources for building new countryside. After making the EFA, the research model initially proposed no change in factors and there are five factors affecting the mechanism of mobilization and utilization of financial resources for building new countryside. After the exploratory factor analysis, these factors will be included in the regression at the next stage to determine the degree of impact of 05 independent variables on the dependent variable.

\subsection{Regression results and analysis}

The regression method used here is the smallest common square method OLS. The coefficient of determination of $\mathrm{R}^{2}$ corrections is used to determine the suitability of the model, the F test is used to confirm the ability of this model to be extended to the whole as well as the $T$ test to reject the hypothesis that the total regression coefficients are equal to zero. Finally, to ensure that the reliability of the last constructed regression equation is appropriate, a series of detections for the violation of the necessary assumptions in the regression linearity is also implemented. The assumptions tested in this section include linear relations, variance of constant residuals, normal distribution of residuals, independence of residuals, multi-collinear phenomena. The results of multiple linear regression show that the model has $\mathrm{R}^{2}=0.730$ and $\mathrm{R}^{2}$ adjusted $=0.727$. The adjusted $\mathrm{R}^{2}$ is smaller than $\mathrm{R}^{2}$, so using it to evaluate the fit of the model will be safer because it does not inflate the suitability of the adjusted $\mathrm{R}^{2}$ model by 0.727 . This indicates that the suitability of the model is $72.7 \%$ or, in other words, $72.7 \%$ of the variation of the variable "Mechanism of mobilization and 
utilization of financial resources" is explained in general by the five independent variables above. Thus, the given linear regression model is suitable with the data and can be used.

Table 4

Results of testing - Analysis of variance (ANOVA)

\begin{tabular}{ccccc}
\hline & Total variance & Degrees of independence & Variance & F \\
\hline Regression & 175.550 & 5 & 35.110 & 256.533 \\
Remainder & 64.873 & 474 & 0.137 & \\
\hline Total & 240.423 & 479 & &
\end{tabular}

The $\mathrm{F}$ test used in analysis of variance is a hypothesis test of the suitability of the overall linear regression model. The meaning of this test is the linear relationship between the dependent variable and the independent variable. ANOVA analysis showed that the parameter $\mathrm{F}=256.533$ with significance level $=0.000$, which proves that the construction regression model is consistent with the data collected and the variables included in the model are statistically significant with significance level $5 \%$. Thus, the independent variables in the model are related to the dependent variable of mobilization and utilization of resources.

Table 5

Regression results

\begin{tabular}{|c|c|c|c|c|c|c|c|}
\hline & \multicolumn{2}{|c|}{$\begin{array}{c}\text { Unstandardized regression } \\
\text { coefficients }\end{array}$} & \multirow[t]{2}{*}{$\begin{array}{c}\text { Standardized regression } \\
\text { coefficients }\end{array}$} & & & \multicolumn{2}{|c|}{ Multicollinearity } \\
\hline & & & & & & Tolerance & Variance inflation factorVIF \\
\hline (Constant) & -0.147 & 0.124 & & -1.183 & 0.237 & & \\
\hline D & 0.109 & 0.024 & 0.118 & 4.624 & 0.000 & 0.878 & 1.139 \\
\hline M & 0.146 & 0.033 & 0.136 & 4.382 & 0.000 & 0.595 & 1.681 \\
\hline Q & 0.259 & 0.025 & 0.301 & 10.524 & 0.000 & 0.694 & 1.441 \\
\hline $\mathrm{N}$ & 0.253 & 0.031 & 0.272 & 8.041 & 0.000 & 0.497 & 2.012 \\
\hline $\mathrm{B}$ & 0.302 & 0.032 & 0.299 & 9.519 & 0.000 & 0.577 & 1.734 \\
\hline
\end{tabular}

The results of the regression show that the coefficients (Beta) of the independent variables D, M, Q, N, B have very small observed values (Sig.) compared to 0.05 , which shows that these variables have a statistically significant impact on the mobilization and use of financial resources for building new countryside. The most powerful variable affecting the mechanism of mobilizing and utilizing financial resources is the viewpoint and objectives of socio-economic development (Q) with beta coefficient $=0.301$. Next is the structural organization and technical facilities $(B)$ with the beta coefficient $=0.299$, followed by the participants' perception variable $(\mathrm{N})($ Beta $=0.272)$, followed by the M variable $($ Beta $=0.113)$ and finally, the characteristics of building new countryside (D) (Beta $=0.111)$, which has the lowest impact on the mechanism of mobilization and use of financial resources. After regression analysis, the authors have tested the hypothesis of linear regression model, especially the hypothesis of the normal distribution of residuals, multicollinearity and variance change, these hypotheses are not infringed. Therefore, the results of linear regression analysis are statistically significant and ensure reliability.

\section{Conclusion and further research directions}

This study has discovered the factors that influence the mobilization and utilization of financial resources to build new countryside in Vietnam - a case study in Nghe An province. The results of the regression analysis show that the factors that have the strongest impact on the mechanism of mobilization and utilization of financial resources are the viewpoint, orientations and objectives of socio-economic development, followed, successively, by structural organization and technical facilities, participants' perception; socio-economic environment and, finally, the characteristics of building new countryside.

Therefore, to complete the mechanism of mobilizing and utilizing financial resources for the construction of new countryside to ensure the effectiveness, economization, efficiency, suitability and stability, it is necessary to focus on improving the viewpoint, orientations and objectives of socio-economic development, followed by structural organization and technical facilities, improving participants' perception. In addition, because the inspection model only reflects $73 \%$ of the research problem, the completion of the mechanism for mobilizing and utilizing financial resources for building new countryside requires adjustments in time when values and positions of these factors change over time and place. Although this study initially identified factors that affect the mobilization and utilization of financial resources for new rural construction, there remain some shortcomings that need to be considered in future studies, such as expanding the interview respondents, the sample size and study area, as the research is currently only conducted in Nghe An province. In addition to the above factors, there may be other factors not yet found. Therefore, it is necessary to continue adding other factors through qualitative research in subsequent studies.

\section{References}

Ammons, D. N., Coe, C., \& Lombardo, M. (2001). Performance-comparison projects in local government: Participants' perspectives. Public Administration Review, 61(1), 100-110.

Diu, D.H. (2017). Mobilizing financial resources for rural transport development in Tuyen Quang province, PhD thesis, Financial Academy. 
Doan, T.H. (2017). Mobilizing and utilizing financial resources to implement the new rural construction program in the Northern Midland and Mountain provinces of Vietnam, PhD Thesis, Central Institute for Economic Management.

Hoang, N.H (2018). Mobilizing and utilizing financial resources for new countryside construction in Ha Tinh province, PhD thesis, The University of Commerce.

Hoang, T.C \& Chu, M.N (2008). Applied statistics in socio-economy. Hanoi: Statistics Publishing House.

Hair, J., Black, W., Babin, B., Anderson, R., \& Tatham, R. (2010). Multivariate Data Analysis New Jersey: Pearson Prentice Hall.

Le, S.T. (2016). Mobilizing and utilizing investment capital for building new rural infrastructure in Hanoi city, PhD thesis, Finance Academy.

Ly, V.T. (2017). Mobilization for new rural construction in Thai Nguyen province. PhD thesis, Thai Nguyen University.

Nguyen, V.C. (2019). Impacts of rural roads on household welfare in Vietnam: evidence from a replication study. Journal of Economics and Development, 21(1), 83-112.

Scoones, I. (1998). Sustainable rural livelihoods: A framework for analysis. IDS Working Paper, No. 72, 86-98.

Simkova, E. (2008). The sustainable development of rural areas and the role of rural tourism. E \& M EKONOMIE A MANAGEMENT, 11(1), 26-32.

Straka, J., \& Tuzová, M. (2016). Factors affecting development of rural areas in the Czech Republic: A literature review. Acta Universitatis Agriculturae et Silviculturae Mendelianae Brunensis, 64(6), 2141-2150.

Prime Minister of Vietnam, Decision No. 800 / QD-TTg dated June 4, 2010, approving the National Target Program on New Rural Construction for the period 2010-2020.

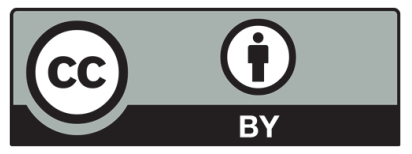

(C) 2020 by the authors; licensee Growing Science, Canada. This is an open access article distributed under the terms and conditions of the Creative Commons Attribution (CC-BY) license (http://creativecommons.org/licenses/by/4.0/). 